\title{
PROFISSIONALIZAÇÃO DO DOCENTE DA EDUCAÇÃO BÁSICA E UNIVERSIDADE PÚBLICA: NOTAS SOBRE A CONSTRUÇÃO DE UMA POLÍTICA (INTER)INSTITUCIONAL ${ }^{52}$
}

\section{PROFESSSIONALIZATION OF THE BASIC EDUCATION AND PUBLIC UNIVERSITY TEACHER: NOTES ON THE CONSTRUCTION OF AN INTERINSTITUTIONAL POLICY}

\author{
Carmen Teresa Gabriel ${ }^{53}$ \\ Joyce Diniz de Abreu Teixeira ${ }^{54}$ \\ Priscila Basilio 55 \\ Silvia Helena Ferreira da Silva ${ }^{56}$
}

\section{Resumo}

O presente trabalho apresenta uma análise preliminar do processo de construção de uma política interinstitucional de formação inicial e continuada de docentes da educação básica Complexo de Formação de Professores (CFP) - de iniciativa da Universidade Federal do Rio de Janeiro (UFRJ). Em diálogo com as contribuições teóricas da abordagem discursiva pósfundacional, e apoiado na literatura especializada da área educacional, em documentos produzidos no âmbito interno do CFP, bem como na vivência das autoras que participam de sua implementação, o texto focaliza o lócus de profissionalização docente - legitimado nessa política em construção - resultante de uma articulação orgânica entre universidade e escolas públicas.

Palavras-chave: Complexo de Formação de Professores. Políticas de formação docente. Universidade Pública. Educação Básica. Profissionalização docente.

\footnotetext{
Abstract

The present work introduces a preliminary analysis of the process of an institutional policy construction, related to the initial and continuous training of teachers of the basic education - Complex of teachers training (Complexo de Formação de Professores/CFP)- an initiative of

52 o Complexo de Formação de Professores é uma iniciativa da UFRJ que articula o ensino superior e a Educação Básica públicos do Rio de Janeiro na construção de uma política interinstitucional de formação inicial e continuada de professores.

${ }^{53}$ Professora Titular de Currículo da Faculdade de Educação da UFRJ. Coordenadora do Comitê Permanente do Complexo de Formação de Professores da UFRJ. E-mail: carmenteresagabriel@gmail.com Telefone:(21)995445743. ORCID: 0000-001-9503-6740

54 Técnica em Assuntos Educacionais da Faculdade de Educação da UFRJ. Mestra em Educação pela UFRJ. Pedagoga e pesquisadora nas áreas de currículo, formação de professores e políticas educacionais. E-mail: joycefeufrj@gmail.com. Telefone: (21)999221432. ORCID: 0000-0002-9879-8641

55 Professora do Colégio de Aplicação da Universidade Federal da UFRJ. Doutoranda em Educação pela UFRJ. Pedagoga e pesquisadora nas áreas de currículo, formação de professores e políticas educacionais. E-mail: cyla_basilio@yahoo.com.br. Telefone: (21) 991674443. ORCID: 0000-0002-2765-857X.

56 Técnica em Assuntos Educacionais da Pró- Reitoria de Extensão da UFRJ. Mestra em Educação pela UERJ. Pedagoga e pesquisadora na área de formação docente e narrativa auto biográfica. E-mail: silviahelenasf@gmail.com Telefone: (21) 998320778. ORCID: 0000-0002-0859-7185.
} 
the Universidade Federal do Rio de Janeiro/UFRJ. In a dialogue with the theoretical contributions of the Postfoundational discursive approach and, supported by the literature pertinent to the field of public policies for the teacher training, in documents produced inside the CFP, as well as supported by the experience of the authors, who participated in its construction, the text focus on the locus of the teacher professionalization, recognized in such policy in constructionandresulting of an organic articulation between university and public schools.

Keywords: Complex of Teachers training.Policies of teacher training. Public university.Basic Education. Teacher professionalization.

\section{Introdução}

A importância de uma coisa não se mede com fita métrica nem com balanças nem com barômetros etc. Que a importância de uma coisa há que ser medida pelo encantamento que a coisa produza em nós (Manoel de Barros).

A questão da formação de professores, inicial e continuada, vem ganhando destaque nos debates educacionais no Brasil, em um contexto político atual no qual proliferam discursos que, em nome de uma 'educação de qualidade', atacam severamente as Universidades e escolas públicas, desvalorizam os saberes e práticas docentes e investem na privatização do sistema educativo como alternativa para resolver as mazelas da Educação. $\mathrm{Na}$ contramão desses discursos, outras leituras apostam na defesa da função social e política da Universidade pública no processo de profissionalização dos professores da Educação Básica, imprimindo outros sentidos ao que se nomeia como 'educação de qualidade'.

Este texto se inscreve, justamente, nesse movimento político mais amplo atravessado pelas lutas pela significação, entre outros, do termo 'qualidade', quando mobilizado para adjetivar educação. Com efeito, em diálogo com autores pós-fundacionais (MARCHART, 2009; RETAMOZO,2009), compreendemos que o jogo político envolvendo a temática em foco se faz em um terreno de disputa no qual múltiplos sentidos e diferentes demandas orientam os debates que mobilizam e definem termos como 'docência', 'profissionalização docente', 'escola', 'universidade' ou 'formação de professores'.

Desse modo, operamos com a ideia de que os debates políticos e epistemológicos sobre formação docente são permeados por processos de significação e ressignificação, em meio a distintas demandas, entendidas, segundo Retamozo (2009), como construções discursivas sociais e históricas que envolvem subjetividades coletivas e diferentes posições dos sujeitos em processos de luta na fixação de sentidos particulares e condensações 


\section{RevistAleph}

significativas resultantes de operações discursivas hegemônicas. ( LACLAU, MOUFFE,2004). Nessa arena discursiva, diferentes sujeitos e grupos sociais buscam negociar, articular, fixar e hegemonizar, mesmo que contingencialmente, determinados sentidos em detrimento de outros. (BALL, 2006; DIAS, 2013; LOPES, 2006a, 2006b)

Interessa-nos mais particularmente, neste texto, entrar nesse debate a partir da análise de uma política (inter)institucional de formação de professores em curso, na UFRJ Complexo de Formação de Professores - buscando compreender potencialidades e desafios da sua produção no que se refere à temática da legitimação do lócus de formação desse profissional. O exercício aqui proposto é menos de avaliar essa política do que explicitar os contornos de um novo arranjo institucional no qual ela tem investido a partir dos princípios político-epistemológicos que orientam a sua construção. Quando as pesquisas da área educacional deixam entrever que a questão do lócus de formação desse profissional tem sido objeto de problematização de forma recorrente, o recorte privilegiado nesta análise assume sua relevância e atualidade. Afinal, qual a importância do lugar legitimado como espaço de formação para a reflexão sobre profissionalização docente? O que esse enfoque territorial diz sobre questões que atravessam essa profissão?

Importa sublinhar que a autoria em muitas mãos deste texto traz as marcas do encantamento que a participação na construção dessa política tem produzido sobre nós, pesquisadoras e professoras. Nosso lugar de fala está atravessado pelas nossas subjetividades. Isso não significa, no entanto, que assumamos uma posição acrítica e façamos aqui a apologia dessa política. Nosso propósito é outro: produzir uma leitura por 'de dentro', sabendo dos riscos que corremos mas, também, da riqueza da singularidade de nossos olhares.

O texto está organizado em duas seções. Na primeira, apresentamos brevemente as linhas de tensão que atravessam os debates recentes do campo educacional voltados para a formação do professor da educação básica que mobilizam e fixam , direta ou indiretamente, sentidos de 'docência', 'universidade' e 'escola'. Para tal, explicitamos o diálogo com e contra estabelecido com pesquisadores, tanto do campo da política quanto o de formação de professores, cujos estudos contribuem para a reflexão sobre a natureza do lugar institucional legitimado como lócus de formação inicial e continuada dos /as professores/as da educação básica. Em seguida, na segunda seção, a partir de pesquisa documental e de nossa experiência 


\section{RevistAleph}

de imersão no processo de construção dessa política, a análise focaliza o arranjo (inter)institucional do Complexo de Formação de Professores, sublinhando as potencialidades e desafios encontrados e os possíveis efeitos produzidos no processo de profissionalização docente.

\section{Políticas de profissionalização docente: contextos e disputas}

Os estudos (GATTI, ANDRÉ, BARRETO, 2011; SARTI, 2012, 2013, 2019; DIAS, 2013; LOPES, 2006a, 2006b) sobre políticas de formação ou profissionalização dos/as professores/as da educação básica têm produzido no campo educacional um volume significativo e consistente de análises, apontando, a partir de diferentes abordagens teóricas, perspectivas e desafios que atravessam os debates sobre essa temática. Como explicitado anteriormente, este texto se inspira no conjunto desses estudos, tendo como recorte uma questão específica que envolve tensões e desafios em torno do lócus da formação desse profissional.

Esse recorte remete diretamente aos debates sobre universitarização (SARTI, 2013, NOVOA, 2017b ) da formação docente, sobre a articulação entre universidade e escola (NOVOA, 2017; ZEICHNER, 2010), bem como sua implicação na relação estabelecida entre sujeitos e entre saberes (POPEKWITZ, 2008) que atuam e são produzidos nesses dois contextos formativos. Neste texto, nos propomos a entrar nesses debates, recorrendo justamente à análise de uma política interinstitucional de formação inicial e continuada de professores, em pleno processo de construção. Dito de outra maneira, interessa-nos pensar os efeitos do reconhecimento do papel incontornável da universidade pública na formação dos professores da educação básica, do investimento em formas não hierárquicas de articulação entre universidade e escola pública, da potência do estabelecimento de relações horizontais entre sujeitos e saberes no processo de produção dos currículos de licenciatura e na valorização do magistério, a partir da refundação de uma institucionalidade que envolve o lócus dessa formação.

Para além do foco explicitado, a reflexão aqui proposta opera com um entendimento de política que autoriza simultaneamente mobilizar esse termo para além das ações do Estado (BALL, 2006) e o diferenciar do significante 'político'(MARCHART, 2009; RETAMOZO, 2009). Em termos da primeira afirmação, trata-se de reconhecer, em nossas análises, que diferentes 


\section{RevistAleph}

contextos formativos - escolas e universidades - são igualmente contextos produtores de políticas (BALL,2012 DIAS,2013; LOPES, 2006a, 2006b). Falar de produção de política de formação de professores implica, pois, incorporar várias escalas espaço-temporais e contextos que embora interligados, apresentam especificidades.

Essa perspectiva permite considerar que o "sistema educativo" e seus problemas de governabilidade não são apenas o reflexo dos problemas de governabilidade que existem na sociedade em seu conjunto. Assim, tem-se, como decorrência, que as linhas de ação governamental implementadas, por exemplo, na direção das redes escolares adquirem significado específico, a depender do contexto sociopolítico e do momento em que são desenvolvidas (GATTI; BARRETO; ANDRÉ, 2011). De modo semelhante, e embora possamos identificar traços comuns em muitas políticas educacionais, em nações e localidades distintas - como os currículos e avaliações docentes pautados em competências e habilidades; o discurso neoliberal e da mercantilização presentes, implícita ou explicitamente, em propostas pautadas na meritocracia, responsabilização e performatividade - defendemos o pressuposto de que elas são constituídas por complexos processos de recontextualização e ressignificação (BALL,2006, LOPES,2006a,2006b), nos quais o "global" e o "particular" hibridizam-se, delineando novos sentidos e múltiplas configurações.

No caso da diferenciação entre política e político, esse enfoque oferece elementos para a compreensão tanto da força da contingência nas lutas pela significação de sentidos de termos disputados nos debates sobre a formação/profissionalização docente ( dimensão do político) quanto das estratégias mobilizadas - no âmbito das políticas de formação inicial e continuada dos docentes -para a estabilização e hegemonização de alguns sentidos particulares em detrimento de outros ( dimensão da política).

Não é por acaso que, nos discursos políticos produzidos e hegemonizados pelo atual governo do Estado brasileiro - sejam eles voltados para a Educação Básica, sejam para o Ensino Superior - sentidos de 'qualidade de educação' tendem a se articular em uma cadeia equivalencial da qual participam termos como 'excelência', 'eficácia, 'habilidades e competências', 'desempenho', 'premiação', 'competição' e 'produtividade'. Não se trata de questionar a pertinência ou não destes significantes 'em si', e sim os sentidos que eles assumem nas políticas educacionais contemporâneas. Esses termos, tal como mobilizados, representam interesses de grupos de reformadores educacionais que apostam e defendem 


\section{RevistAleph}

ideias pautadas no gerencialismo, na meritocracia, na privatização e/ ou na responsabilização docente, provocando efeitos nos processos de ensino, aprendizagem e avaliação, na organização dos tempos e práticas escolares e, consequentemente, na formação de professores e professoras, bem como no próprio sentido de 'profissionalização docente'.

Discutir política de formação de professores, hoje, implica, portanto, reconhecer as tensões existentes nessas disputas de sentidos e situar esta temática no enfrentamento "das consequências da comodificação da educação, da influência de organizações empresariais, da precarização do trabalho e da inédita mercantilização da educação superior em curso no país" (GABRIEL \& LEHER, 2019, p.220).

Em estudo relativamente recente, Nóvoa (2017a) aponta que, para resistir a esse movimento mercantilista que procura se firmar como alternativa no campo da formação docente inicial e continuada, é preciso investigar como esta vem ocorrendo, identificar seus problemas e, a partir daí, pensar em possíveis soluções. Como as políticas de formação docente no Brasil, nos últimos anos, tem impactado o trabalho dos professores?

Como mencionado anteriormente, a análise da literatura especializada da área de formação docente há tempos vem apontando que um dos desafios a serem enfrentados diz respeito ao lugar institucional legitimado como espaço propício e fecundo para essa formação. Nesse movimento se inscrevem justamente os debates sobre o nível de ensino a que essa formação estaria associada, mais especificamente quando se trata de professores dos anos iniciais, à importância atribuída aos diferentes contextos - universidade e escola que participam diretamente dessa formação, ou ainda as tensões entre os cursos de bacharelado e licenciaturas em busca de prestígio e reconhecimento no seio da própria cultura universitária. A essas diferentes portas de entrada nesse debate, se somam a ampliação e intensificação de cursos de formação de professores à distância mediadas por meios tecnológicos e longe dos espaços acadêmicos institucionais.

Importa sublinhar, contudo, que esse desafio não se limita a uma dimensão territorial. Ele está diretamente atrelado ao perfil do profissional docente ou ao processo de identificação com o ofício docente, no qual se pretende investir. Isso significa afirmar que a defesa de um ou outro lócus institucional de formação depende diretamente da concepção de docência pela qual se luta. As disputas envolvendo Escola Normal e universidade, o lugar simbólico e efetivo ocupado pela formação docente no seio da cultura universitária ou ainda 


\section{RevistAleph}

o papel atribuído à escola nesse processo mobilizam pois, os múltiplos sentidos de docência e particularmente de 'saberes docentes' (TARDIF, 2002; SHULMAN,2005) legitimados nesses contextos. Falar, pois, de lócus, é falar igualmente de saberes e sujeitos envolvidos nesse processo formativo.

Como deixa entrever o título atribuído a este texto, a política interinstitucional específica trazida como objeto de reflexão, aposta na importância da universidade pública no processo formativo do docente da educação básica e simultaneamente assume de forma explícita a associação entre formação docente e profissionalização. Esses posicionamentos remetem a debates internos ao campo educacional e sua sustentação exige argumentos que vão além de afirmações de princípios.

No que diz respeito à importância e à legitimação da universidade pública como espaço de profissionalização dos/das professores/as da educação básica, estudos como os de Gatti, Barreto e André (2011) apontam que o movimento de universitarização não teria sido necessariamente suficiente para garantir a valorização do profissional da educação básica. Segundo essas autoras, a formação de professores em nível superior ofertada pelas IES oferecia um caráter questionável, pois se percebia pouco avanço no preparo do docente para enfrentar os desafios relativos à sala de aula. Observou-se, no período estudado, uma imobilidade muito grande nas instituições universitárias, nas instituições de nível superior, no sentido de apresentar proposições mais avançadas e consistentes para formar professores. De acordo com as pesquisadoras, a formação de professores nas Universidades públicas vem sendo relegada a um plano secundário, tendo em vista que a prioridade, no âmbito da cultura universitária, ainda é para pesquisa. Em sua análise sobre a realidade educacional brasileira, Nóvoa (2017a), corrobora com a análise de Gatti, Barreto e André (2011), afirmando que “[...] são muitos os sinais que ilustram a desvalorização e desprestígio da formação de professores no contexto universitário, desde a fragmentação dos cursos até as práticas de 'menosprezo' pelas licenciaturas" (NÓVOA 2017a, p.7).

Em linhas gerais, se há convergências, entre grande parte dos estudiosos da área, sobre a pertinência de continuarmos investindo no processo de universitarização da formação de docentes que atuam na rede de escolas da educação básica, o mesmo não acontece quando se trata de explicitar as ações específicas relacionadas diretamente à formação desse profissional desenvolvidas no âmbito da cultura universitária ou a natureza 


\section{RevistAleph}

da articulação entre esses dois espaços de formação e atuação profissional. Quais os efeitos políticos e epistemológicos desse processo na forma de pensar e efetivar a articulação entre universidade e escola? Como se caracteriza a articulação entre os sujeitos e seus respectivos saberes que atuam nesses dois contextos formativos? De que forma esse processo de universitarização contribui para reforçar e/ou desestabilizar alguns dos binarismos clássicos 'teoria -prática', 'ciência-pedagogia','bacharelado-licenciatura', 'pesquisa-ensino' - que atravessam os debates sobre formação de professores? Esses são alguns exemplos de questionamento cujas respostas não traduzem consenso no seio da comunidade acadêmica.

Em meio a esses debates se destaca um conjunto de argumentos que se sustentam na crítica à forma historicamente hegemonizada de como a Universidade se relaciona com as escolas e seus profissionais. Entre essas formas, a que ficou conhecida como o 'modelo $3+1$ ' (três anos de bacharelado e uma ano de licenciatura), pelo qual a formação pedagógica é percebida como uma complementação, um apêndice da formação teórica de cada área disciplinar na fase conclusiva do bacharelado, foi, até época recente, a mais estabilizada. Nessa formulação, marcada pela separação entre a área de conhecimento disciplinar específica e a área de conhecimentos pedagógicos para a docência, a entrada na escola da educação básica, ao se reduzir ao estágio, se faz de forma secundária e relativamente tardia, dificultando a consolidação de um curso de licenciatura de identidade profissional própria.

Importa sublinhar que, embora esse modelo já tenha sido exaustivamente problematizado e legalmente extinto há quase duas décadas, os pressupostos epistemológicos e políticos nos quais ele se institui tendem a permanecer na cultura universitária e pautar a relação desta com a escola pública. Como sinalizam Gatti, Barretto e André (2011) ao fazerem referência as Diretrizes Curriculares Nacionais publicadas em 2002, que tinham como objetivo uma revisão dos aspectos que marcaram a formação de professores até esse momento, para que lhes fosse garantido uma formação profissional:

(...) mesmo com ajustes parciais propostos nessas diretrizes, verifica-se, nas licenciaturas dos professores especialistas, a prevalência da histórica ideia de oferecimento de formação com foco na área disciplinar específica, com pequeno espaço para a formação pedagógica (GATTI, BARRETTO E ANDRÉ, 2011 p. 98).

As críticas a esse modelo incidem, em geral, no fato de que essa relação se baseia em um modelo "de fora para dentro", no qual o conhecimento é propriedade exclusiva ou 


\section{RevistAleph}

preferencialmente de acadêmicos /pesquisadores, reafirmando assim, um sistema de saberes hierarquizado e excludente. Nessa perspectiva, a relação singular que os professores da educação básica estabelecem com o conhecimento é subalternizada. O ato de ensinar é reduzido à capacidade instrumental de transmissão de um saber produzido em outro lugar.

Em termos do entendimento da docência como profissão, é possível igualmente evidenciar que os defensores dessa associação não encontram caminho fácil para reafirmá-la como princípio político de orientação para formulação das políticas voltadas para os professores da educação básica. Significantes como, por exemplo, 'missão', 'sacerdócio', 'bico' são frequentemente mobilizados nas cadeias de definição do termo docência, reatualizando assim discursos sobre a docência, antagônicos àqueles que investem na interface professor/a-profissional. Compreender a docência como profissão pressupõe reconhecer que ela estabelece uma relação particular com o conhecimento científico, e como tal não se reduz à transmissão de saberes produzidos em outros espaços, mas sim exige, uma produção singular e contextualizada no cotidiano, envolvendo a articulação crítica e epistemologicamente fundamentada entre diferentes espaços, sujeitos e saberes.

A reflexão que subjaz a política interinstitucional que vem sendo gestada no âmbito do Complexo de Formação defende não somente que a docência é uma profissão, mas também que a formação desse profissional se faz por dentro da profissão(NÓVOA, 2017). Isso significa atribuir à escola da educação básica um lugar incontornável nesse processo formativo, uma vez que essa instituição é o lócus de atuação profissional, por excelência. Como argumenta Nóvoa é preciso conceder "aos professores mais experientes um papel central na formação dos mais jovens" (NÓVOA, 2009, p. 36). Isso significa investir no "entrelaçamento entre as escolas e a universidade, entre os professores da educação básica e da universidade, para, em conjunto, construírem os processos de formação dos mais jovens" (NÓVOA, 2017a, p. 17).

Esse autor salienta, ainda, que o aprimoramento da formação continuada passa por um investimento nos projetos educacionais da escola, no estímulo da autonomia docente e na criação de redes de autoformação que possibilitem a troca de experiências entre professores de diferentes instituições. Evidencia-se, assim, que a formação precisa acontecer de modo horizontal com e não para os professores.

Nessa mesma linha argumentativa, Nóvoa, inspirado no estudo de Zeichner, Payne e 


\section{RevistAleph}

Brayko (2015) afirma que "para enfrentar o movimento para desmantelar o sistema universitário de formação de professores, substituindo-o por um conjunto de programas empresariais que vão piorar a já difícil situação das escolas públicas e do professorado" (NÓVOA, 2017) é preciso, primeiramente, reconhecer a necessidade de mudanças profundas na área de formação docente.

Entre os desafios relacionados ao reconhecimento de mudança, a mais preconizada e, paradoxalmente, a de maior dificuldade de enfrentamento consiste justamente na compreensão do lócus mais propício para essa formação quando se reconhece a necessidade do combate às polaridades e hierarquias- pesquisa e ensino, teoria e prática, bacharelado e licenciatura, ciência e pedagogia - que atravessam a formação docente. O que está em jogo é a construção de espaços-tempos híbridos que, ao romperem com essas dicotomias oferecem possibilidades outras para a reflexão sobre a formação inicial e continuada desse profissional.

Não é por acaso que nessas últimas décadas expressões como 'terceiro espaço' (ZEICHNER, 2010) ou 'casa comum' (NÓVOA, 2017b) emergem nos estudos dos especialistas da área para nomear essas outras possibilidades. A constituição desse 'terceiro espaço pressupõe a afirmação de um lugar institucional que promova relações horizontais entre Universidade e escola e que operem com a lógica da incompletude, ao invés da complementariedade (GABRIEL, 2019).

Nesse sentido, o entendimento desse terceiro espaço requer o fortalecimento de um modo outro de pensar a articulação entre essas duas instituições, percebidas respectivamente como contextos formativos, produtoras de conhecimentos sobre formação docente que são simultaneamente indispensáveis, insuficientes, incompletos, inacabados e provisórios. Isso significa desestabilizar tanto os discursos que alimentam a pretensão da universidade em 'iluminar' a escola, sintetizado na frase, muitas vezes mobilizada, "a universidade vai à escola" quanto aqueles que negam, em nome da apologia de um entendimento de prática como um lugar esvaziado de teoria, as contribuições da cultura universitária no processo formativo do docente da educação básica. Afinal, como afirma Nóvoa, o "segredo deste 'terceiro lugar' está numa fertilização mútua entre a universidade e as escolas, na construção de um lugar de diálogo que reforce a presença da universidade no espaço da profissão e a presença da profissão no espaço de formação" (NÓVOA, 2017b ,p.1116). 


\section{RevistAleph}

Nesse sentido, as inter-relações entre a Educação Superior e a Educação Básica agenciam reflexões e regulam novos conhecimentos, desconstruindo a ideia de que na primeira há a produção do conhecimento teórico, que é aplicado pela segunda, por meio de uma relação unívoca. De forma semelhante, as ações desenvolvidas no contexto da Educação Básica também subsidiam reflexões para reconfiguração dos currículos de licenciatura. .

Considerando os limites deste texto e como já explicitado, optamos por centrar nosso olhar na interface lócus de formação -profissionalização docente. Além de um eixo clássico nos debates sobre política de formação de professores/as, a escolha desse recorte se justifica pelo fato de ele permitir explorar contornos da institucionalidade da política, objeto de nossa reflexão neste texto, o que, como procuraremos sustentar, traduz (ou busca traduzir) a sua potência inovadora. Afinal, trata-se de pensar no caso do Complexo de Formação, como escola e universidade públicas se articulam do lugar de contextos produtores de política para estabilizar sentidos particulares de 'qualidade', 'formação/profissionalização docente', 'docência', 'universidade' e 'escola'.

\section{Arranjo (inter)institucional do Complexo de Formação: o que há de 'novo' sob o sol ?}

O Complexo de Formação de Professores (CFP), em pleno processo de construção coletiva envolvendo diferentes parceiros institucionais, pode ser vista como uma aposta política e epistemológica de rearranjo institucional que vem sendo gestada, por iniciativa da UFRJ, há mais de três anos (GABRIEL, 2019). Ela emerge com o intuito de dar conta dos desafios e demandas do campo educacional que vão ao encontro dos movimentos em defesa das instituições públicas - universidade e escola- percebidas como espaços potentes de profissionalização.

Desse modo, menos do que evidenciar novas questões ou desafios relacionadas à formação desse profissional, o Complexo de Formação de Professores (CFP) pretende potencializar as condições objetivas e subjetivas - já há muito assinaladas por estudiosos críticos das políticas oficiais em curso - para desestabilizar discursos hegemonizados e oferecer uma formação que possa ser plena e intensamente vivenciada e fundamentada do ponto de vista teórico. Construída a partir da metáfora da 'casa comum' (NÓVOA, 2017b), essa política sinaliza possibilidades de outros arranjos interinstitucionais que possam criar uma ambiente propício para a amplificação das potências de uma rede/malha formativa de 


\section{RevistAleph}

tamanha complexidade.

Nessa perspectiva, essa política tem focalizado prioritariamente as estratégias e processos de institucionalidade que a permitem ocupar o lugar do que Zeichner (2010) nomeia, como vimos anteriormente, do 'terceiro-espaço' no qual outras articulações entre territórios, sujeitos e saberes possam se pautados a partir de princípios como o da 'horizontalidade', 'pluralidade' e 'integração', expressos no 'Termo de Compromisso' produzido coletivamente por diferentes instituições parceiras no ano de 2018. Assim, ao invés de se apresentar como um "novo" modelo de formação docente, o CFP se propõe a investir em uma refundação do arcabouço institucional que regula a formação inicial e continuada dos professores da educação básica de forma a garantir uma articulação orgânica entre diversas ações formativas, gestores e professores das IFEs e das escolas da educação básica que delas participam, configurando uma densa e rica malha formativa. Para tal essa política tem investido: (i) na reflexão sobre o papel das IES no processo de profissionalização docente e no debate sobre a natureza da articulação pretendida com as escolas da Educação Básica (ii) no enfrentamento do desprestígio dos cursos de Licenciaturas na cultura universitária, percebidos, muitas vezes como bacharelados de segunda ordem; (iii) na construção de um 'comum' ( DARDOT, LAVAL, 2017, GABRIEL, 2019) possível, pautado em processos democráticos, dialógicos, de forma a reposicionar o papel a formação docente inscrito numa política institucional integrada; (iv) na ampliação do diálogo com as redes de escolas de Educação Básica com o intuito de constituir um grupo de escolas parceiras (GEP); (v) em reuniões periódicas, internas às IFES parceiras envolvendo as suas respectivas instâncias acadêmicas que se relacionam direta e indiretamente com as licenciaturas com o intuito de buscar estratégias de capilarização das discussões e de institucionalização junto às instâncias deliberativas das instituições universitárias parceiras (vi) em reuniões sistemáticas entre os representantes das instituições parceiras; (vii) no desenvolvimento de uma Experiência Piloto, em 2019, que representou o primeiro passo para a sua implementação.

É pois, em meio a esses movimentos e estratégias foi se forjando, na UFRJ, o desenho institucional dessa política de formação de professores da educação básica. Esse desenho foi pensado com o intuito de traduzir institucionalmente a ideia de 'terceiro espaço' ou 'casa comum' tal como definido respectivamente por Zeichner (2010) e Nóvoa (2017) , como lócus de formação privilegiado. O que está em jogo é portanto, a invenção de um novo arranjo 


\section{RevistAleph}

institucional que possa funcionar como um 'entre-lugar', entendido como um espaço comum entre a cultura universitária e a cultura escolar.

É nessa lógica, que se inscreve a proposta de constituição do Grupo de Escolas Parceiras (GEP) composto por escolas públicas localizadas no Estado do Rio de Janeiro, pertencentes às diferentes redes - municipal, estadual e federal - e que junto com as instituições federaisdo Ensino Superior pertencentes a essa malha de formação inicial e continuada configuram o embrião de uma nova institucionalidade. A construção dos Núcleos de Planejamento Pedagógico das Licenciaturas (NPPL), dos Grupos de Orientação Pedagógica (GOP) ou ainda das Redes de Educadores de Prática de Ensino (REPs) traduzem igualmente as formas de interiorização dos princípios hegemonizados nessa política. Para além dessas instâncias nas quais essa política se desdobra - respeitando às suas especificidades internamente em cada IFES, o arranjo (inter)institucional prevê igualmente a constituição de um Fórum Permanente de Formação de Professores do qual participam os representantes máximos de todas as instituições parceiras. A seguir, apresentamos quatro aspectos ou dimensões que orientaram a construção do desenho institucional do CFP e que explicam e justificam essas diferentes instâncias

O primeiro aspecto diz respeito à valorização da escola como lócus de formação inicial do futuro profissional, bem como de formação continuada para os profissionais que nela atuam. Formar professores dentro da profissão implica em colocar os holofotes sobre a escola como um espaço privilegiado, no qual os professores passam a ocupar um papel central na formação inicial dos futuros docentes, em coparticipação com os professores universitários. Para isso, é preciso criar condições para aproximar os licenciandos do cotidiano escolar, incluindo nos currículos dos cursos de licenciaturas disciplinas/atividades que tenham este propósito, favoreçam essa imersão e amplifiquem a interlocução dos estudantes com os profissionais da escola, seja na universidade ou nas próprias escolas, desde os primeiros períodos, oferecendo subsídios para o processo de deslocamento da posição de estudante universitário para o de docente da educação básica.

A valorização da escola como aqui defendido, pressupõe que ela seja compreendida como um espaço de profissionalização permanente que se organiza e se regula como tal, a partir das demandas de formação formuladas pelos próprios sujeitos posicionados como gestores/as e professores/as que atuam em uma cultura escolar específica. A criação dos 


\section{RevistAleph}

Grupos de Escolas Parceiras (GEP) representa a estratégia adaptada no Complexo para assegurar essas diferentes dimensões da valorização da escola como espaço formativo. O foco da parceria entre escola e universidade se desloca dos indivíduos para as instituições. Esse deslocamento ao invés de apagar ou negar a potência criativa de cada docente, permite potencializar o reconhecimento desse/a profissional como formador e produtor de conhecimento específico (TARDIF, 2002; TARDIF, LESSARD, LAHAYE 1991; SHULMAN, 2005) e da sua participação efetiva na produção de políticas voltadas tanto para a formação de seus futuros colegas quanto para sua própria formação e de seus pares em meio à cultura escolar na qual ele/a se insere.

Entendemos assim, que essa estratégia pode contribuir simultaneamente para deslocar o/a professor/a da educação básica" do lugar do morto", ou do "referencial passivo" (NÓVOA, 1995; SARTI, 2012) na formação de seus futuros colegas de profissão, reforçando sua autonomia como professores que, posicionados simultaneamente como sujeitos políticos, do conhecimento e de desejo, produzem relações particulares com o conhecimento e avaliam as suas necessidades e/ou interesses de formação continuada.

Esse primeiro aspecto ressaltado do desenho institucional do Complexo de Formação de Professores produz impacto na reflexão sobre a escolha da natureza e do momento de inclusão nos currículos ao longo da trajetória de formação do licenciandos das diferentes ações formativas que mobilizam diretamente a articulação com a escola. Referimo-nos, mais especificamente, ao papel dos estágios, das ações extensionistas e da pesquisa na formação profissional.

Nessa perspectiva, as REPs exercem um papel fundamental na discussão e reconfiguração das ações relacionadas ao estágio obrigatório dos cursos de Licenciaturas, na mediação das interlocuções, na amplificação da experiência profissional e dos processos de ensino e aprendizagem que este momento proporciona a todos os que dele participam. A composição híbrida dessas redes, constituída por docentes das IES e da escolas de Educação Básica parceiras, permite a constituição de um espaço privilegiado na construção da cultura profissional e na transição da posição de estudante para a posição de professor. Este grupo tem por objetivo acompanhar os licenciandos nesta etapa, atuando tanto na amplificação da interlocução de professores e futuros professores em diferentes momentos do processo formativo, quanto no apoio do enfrentamento dos desafios nos primeiros anos do exercício 


\section{RevistAleph}

profissional. O trabalho integrado entre universidade e escola abre novas perspectivas no planejamento de atividades que favoreçam a inserção destes ingressantes no cotidiano da escola. O diferencial, aqui, refere-se mais à inscrição das práticas de estágio em uma nova institucionalidade - pretendida em meio à emergência desse terceiro-espaço - do que uma inovação no seu entendimento. Afinal, ações de estágio bem sucedidas podem ser encontradas em diferentes licenciaturas da UFRJ e demais IES. No entanto, o alcance dessas ações tende a se limitar ao campo de atuação de profissionais que agem muitas vezes de forma solitária e isolada. As redes de prática de ensino (REPs) pensadas no âmbito do Complexo buscam justamente romper esse isolamento, bem como abrir espaço para o desenvolvimento de ações conjuntas na cultura escolar que possam valorizar efetivamente o professor da escola pública como formador de seu futuro colega.

Além do estágio, outras vivências são potentes para a imersão dos estudantes no universo escolar, dentre os quais destacamos a participação em ações de extensão e pesquisa, bem como em equipes de trabalho interinstitucionais. A extensão, por ser "um processo interdisciplinar educativo, cultural, científico e político que promove a interação transformadora entre universidade e outros setores da sociedade" (FORPROEX, 2010), tornase um lugar propício para entrelaçamentos da sociedade, universidade e escola que pode ser oferecido nos momentos iniciais do percurso formativo dos licenciandos, antecipando positivamente os encontros do futuro docente com a sua cultura profissional. Aqui, também, os profissionais da escola pública têm um papel de destaque nestas ações, como atores, interlocutores e produtores de conhecimento.

As ações formativas relacionadas à pesquisa também podem ser igualmente redimensionadas nessa política de valorização da escola como espaço formativo. Trata-se, assim, de fortalecer a via de mão-dupla universidade-escola, nos processos investigativos, no compartilhamento e reflexão a partir do que foi produzido no trabalho de investigação. Essa malha formativa pode ser percebida como um campo empírico e reflexivo para os diferentes sujeitos que contribuem para a sua tessitura.

O segundo aspecto refere-se à dimensão coletiva/colaborativa no enfrentamento da cultura isolacionista tradicionalmente hegemonizada em instituições como escola e universitária públicas. Por ser uma rede formativa, que envolve diferentes sujeitos e instituições, o Complexo de Formação de Professores por meio de suas instâncias, em 


\section{RevistAleph}

particular os NPPLs, contribui para que sejam forjadas modalidades mais interativas de formação, que amplifiquem a troca de saberes tanto no âmbito das IFEs quanto das escolas. Entre as diversas configurações de trabalho integrado passíveis de serem estimulados e desenvolvidos no âmbito desses Núcleos de Planejamento Pedagógico, destacamos: i) grupos de trabalho por instituição e/interinstitucionais para discutir e produzir diferentes conhecimentos/ ações relativos a políticas educacionais; projetos educativos; metodologias de ensino; currículo; materiais didáticos, situações escolares cotidianas, dentre outros; ii) grupos de trabalho interinstitucionais, constituídos por licenciandos, professores universitários, professores e demais profissionais da Educação Básica, co responsáveis pelo planejamento e execução de ações integradas de ensino, pesquisa e extensão, voltadas tanto para a formação inicial como continuada, realizadas nas IES, escolas e outros espaços formativos; iii) comunidades de formação e aprendizagem (virtuais ou semipresenciais) constituídas por licenciandos, professores universitários, professores da Educação Básica (mais experientes / ingressantes) e demais profissionais das instituições parceiras, com foco na discussão reflexiva e investigativa do cotidiano escolar e das práticas educativas

Para que essas trocas e articulações possam ser efetivadas, entendemos que seja necessário romper, todavia, com a cultura isolacionista que predomina nos espaços educativos, em diferentes níveis e que reforçam uma forma individualista de exercer a prática docente e a compartimentação dos saberes no âmbito interno das IFES integrantes do grupo de instituições parceiras. Afinal, como apontam Gabriel e Leher (2019):

(...) pensar a profissionalização de professores da educação básica no âmbito do Complexo de Formação de Professores é construir, em meio à articulação entre cultura universitária e cultura escolar, percursos curriculares que permitam que, ao longo de toda a sua formação, o/a licenciando/a, possa estabelecer, por meio de seu envolvimento nas diferentes atividades acadêmicas - pesquisa, ensino e extensão, relações virtuosas e pujantes com diferentes saberes, consigo mesmo, com os outros e com o mundo (GABRIEL, LEHER, 2019, p. 11).

Nessa mesma linha de pensamento, se justifica a proposta de criação de uma ferramenta digital - a Cartografia - com o intuito de dar visibilidade e viabilizar o trabalho cooperativo e integrado entre equipes do bacharelado e da licenciatura, dos diferentes cursos, que pode ser profícua no sentido de valorização da complementaridade de seus saberes específicos. Essa ferramenta digital foi pensada para materializar os princípios que 


\section{RevistAleph}

norteiam o CFP. Ela dá visibilidade a um conjunto de possibilidades formativas oferecidas pelas diferentes instituições parceiras e endereçadas tanto aos professores em exercício quanto aos futuros profissionais em formação inicial. Em cada semestre letivo ela é atualizada deixando entrever possíveis percursos para aquele período específico em função dos interesses e demandas de cada . Importante sublinhar que a cartografia não é apenas uma ferramenta de divulgação das múltiplas atividades. Ela é a porta de entrada para os caminhos a serem percorridos no processo formativo. Isso significa que qualquer inscrição em alguma das ações oferecidas pressupõe certificação e/ou diplomação (para os professores da rede) ou creditação (para os licenciandos) segundo as normas dos cursos de licenciatura da UFRJ para cada tipo de ação acadêmica (pesquisa, ensino e extensão).

O acolhimento sistemático de licenciandos e orientação em seu percurso acadêmicoprofissional é o terceiro aspecto que merece ser destacado. O acolhimento pelos GOPs aos calouros dos cursos de Licenciaturas é uma das ações estratégicas mobilizada nessa política para a afirmação de cursos de licenciatura com identidade própria, reconhecidos como tais no âmbito da cultura universitária. Tendo como atribuição o acolhimento e acompanhamento ao longo dos três primeiros períodos, esses Grupos de Orientação Pedagógica, formados por grupos relativamente pequenos de professores e de estudantes, distribuídos pelos diferentes cursos de licenciatura, têm o papel de ajudar a inserção desses últimos na cultura universitária, ouvindo suas dúvidas e preocupações e, principalmente, com base em suas experiências prévias e interesses, apresentá-los às inúmeras ações formativas atualizadas e socializadas semestralmente por meio da ferramenta digital Cartografia anteriormente mencionada: (i) disciplinas optativas de seu curso e outros cursos, em sua instituição de ensino ou em outras IES parceiras; (i) cursos, seminários, conferências, eventos culturais, (iii) projeto de extensão, (iv) laboratórios de pesquisa ou demais atividades acadêmico-culturais ofertadas pelas diferentes instituições parceiras.

E por fim, mas não menos importante, destacamos a força política da dimensão inter(institucional) da articulação buscada, envolvendo diversas unidades e instâncias de uma mesma instituição (Comitê Permanente) bem como as diferentes instituições parceiras (Fórum Permanente). No caso da articulação interna a cada instituição o que está em jogo é a possibilidade de criação de uma lugar que responda institucionalmente pelas demandas de formação docente que interpelam as IFEs. A aposta consiste em afirmar que uma maior 


\section{RevistAleph}

visibilidade institucional favorece o deslocamento da licenciatura do lugar da subalternidade que historicamente tem Ihe sido atribuída pela cultura universitária.

Em termos da articulação entre as instituições parceiras, essa força política é redimensionada. A despeito de suas especificidades, essas instituições convergem na defesa das instituições públicas de ensino autônomas, bem como a valorização da profissão docente. A previsão da criação de um Fórum Permanente de Formação de Professores de natureza deliberativa, com o intuito de discutir, avaliar, problematizar e propor políticas educacionais voltadas para a formação inicial e continuada de professores da educação básica, de forma coletiva e colaborativa, representa um esforço de reconfiguração institucional de escala até então, desconhecida.

\section{Alguns alinhavos}

No momento desta escrita, todas essas instâncias que configuram o desenho institucional proposto estão em pleno processo de implementação em ritmos e avanços diferenciados em função do grau de capilarização desse debate e dessa proposta em cada unidade e/ou instituição.

Pela sua natureza, a política em foco nessa reflexão precisa ser vista como um processo permanente e inacabado. Não se trata, pois, de trabalhar em prol da construção de um modelo formação alternativo e definitivo. O que está em jogo é menos a chegada do que as possibilidades abertas para que outros caminhos possam ser percorridos. Com erros e acertos, o mais importante é assumir do lugar de instituições públicas - escola e universidades

- os seus respectivos papéis como produtoras de políticas. Políticas essas que possam contribuir para estabilizar, sedimentar, ainda que provisoriamente, sentidos particulares de docência nos quais nos interessa investir como profissionais da educação.

Ao se pautar no compromisso da universidade e da escola públicas com a formação inicial e continuada docente, na afirmação da docência como profissão e na defesa da valorização do professor da educação básica, essa política deixa claro o seu posicionamento nas disputas pela interpretação e instituição do mundo no qual vivemos. Mais do que configurar uma rede ou malha formativa, o Complexo de Formação de Professores de iniciativa da UFRJ pretende se inscrever no cenário político educacional como um novo arranjo (inter)institucional que permite ressignificar o comum como princípio político 


\section{RevistAleph}

(DARDOT, LAVAL, 2017). O desafio que temos pela frente é do tamanho da vontade política que nos alimenta e nos instiga a continuar.

\section{Referências}

BARROS, M. Memórias Inventadas: A Segunda Infância. São Paulo: Planeta, 2006.

BALL, S. J. Sociologia das políticas educacionais e pesquisa crítico-social: uma revisão pessoal das políticas educacionais e da pesquisa em política educacional. Currículo sem Fronteiras. v. 6, n. 2, p. 10-32, jul./dez. 2006. Disponível em:

http://www.curriculosemfronteiras.org/vol6iss2articles/ball.pdf.

BALL, S. J. Reforma educacio barbárie social: economismo e o fim da autenticidade. Práxis Educativa, Ponta Grossa, v. 7, n. 1, p. 33-52, jan./jun. 2012.

BRASIL, Conselho Nacional de Educação. Resolução CNE/CP no 1, de 18 de fevereiro de 2002. Institui Diretrizes Curriculares Nacionais para a formação de Professores da Educação Básica, em nível superior, curso de licenciatura, de graduação plena. Brasília, DF: Ministério da Educação/Conselho Nacional de Educação, 2002.

COMPLEXO DE FORMAÇÃO DE PROFESSORES, Termo de Compromisso, UFRJ, 2018.

DARDOT, Pierre; LAVAL, Christian. Propriedade, apropriação social e instituição do comum Tempo social, São Paulo, v. 27, n. 1, p. 275-316, jun. 2015.

DIAS, R. E. Demandas das Políticas Curriculares para a Formação de Professores no Espaço Iberoamericano. Revista e-Curriculum (PUCSP), v. 11, p. 461-478, 2013.

FÓRUM DE PRÓ-REITORES DA EXTENSÃO DAS UNIVERSIDADES PÚBLICAS BRASILEIRAS. Avaliação Nacional da Extensão Universitária. (Coleção Extensão Universitária; vol. 3). Brasília: MEC/SESu; Paraná: UFPR; Ilhéus (BA): UESC, 2001. Disponível em:

http://www.renex.org.br/documentos/Colecao-Extensao-Universitaria/03- Avaliacao-Nacional-daExtensao/Avaliacao

GABRIEL, Carmen Teresa. Docência, demanda e conhecimento escolar: articulações em tempos de crise. Currículo sem Fronteiras, v. 15, n. 2, p. 425-444, maio/ago. 2019.

GABRIEL, Carmen Teresa. Complexo de Formação de Professores: uma experiência (inter)institucional em curso. Revista de Currículum y formación del profesorado, vol.23, $n^{\circ} 3$, julho/setembro 2019.

GABRIEL, Carmen Teresa. Currículo e construção de um comum: articulações insurgentes em uma política institucional de formação docente. Revista e-curriculum (PUCSP), v. 17, p. 1545-1565, 2019.

GABRIEL, C. T; LEHER, R. Complexo de Formação de Professores da UFRJ: Desafios e apostas na construção de uma política institucional. Formação em Movimento, v.1, n.2, p. 219-237, jul./dez. 2019.

GATTI, B. A.; BARRETO, E. S. S.; ANDRÉ, M.

E. D. A. Políticas Docentes no Brasil: um estado da arte. Brasília: MEC / UNESCO, 2011. 
LACLAU, E.; MOUFFE, C. Hegemonía y estratégia socialista. Hacia una radicalización de la democracia. Buenos Aires: Fondo de Cultura Económica de Argentina, 2004

LOPES, A. C. Discursos nas políticas de currículo. Currículo sem fronteiras, v.6, n.2, p.33-52, jul/dez. 2006a. Disponivel em: http://www.curriculosemfronteiras.org .

LOPES, A. C. Relações macro/micro na pesquisa em currículo. Cadernos de Pesquisa. São Paulo. V.36, p. 619-635, set/dez, 2006b.

MARCHART, O. El pensamiento político posfundacional: la diferencia política en Nancy, Lefort, Badiou y Laclau. Buenos Aires: Fondo de Cultura Económica, 2009.

NÓVOA, A. Profissão Professor. Porto: Porto Editora, 1995

NÓVOA, A. Professores: imagens do futuro presente. Lisboa: Educa, 2009.

NÓVOA, A. Complexo de Formação de professores: um novo modelo institucional para a formação de professores na Universidade Federal do Rio de Janeiro. Relatório de final de missão institucional. (2017a)

NÓVOA, A. Firmar a posição como professor, Afirmar a profissão docente, Cadernos de Pesquisa Fundação Carlos Chagas, V.47, n.166, p.1106-1133, out/dez. (2017b).

POPKEWITZ, T. Cosmopolitanism and the age of school reform: Science, education, and making society by making the child. New York: Routledge, 2008.

RETAMOZO, M. Las demandas sociales y El estúdio de los movimientos sociales. Cintia Moebio, Santiago, v. 35, p. 110-127, 2009.

SARTI, F. M. O triângulo da formação docente: seus jogadores e configurações. Educação e Pesquisa, 38 (2), 323-338, 2012.

SARTI, F. M. Pelos caminhos da universitarização: reflexões a partir da masterização dos IUFM franceses. Educação em Revista, 29(4), 215-244. DOI: doi.org/10.1590/S0102-46982013000400010, 2013

SARTI, F. M. O curso de pedagogia e a universitarização do magistério no Brasil: das disputas pela formação docente à sua desprofissionalização. Educação e Pesquisa, 45, e190003. Epub May 09, 2019. DOI: doi.org/10.1590/s1678- 4634201945190003, 2019.

SHULMAN, Lee S. Conocimiento y enseñanza: fundamentos de la nueva reforma. Profesorado. Revista de Currículum y Formación de Profesorado. v.9, n.2, Granada, España, pp.1-30, 2005.

TARDIF, M.; LESSARD, C. \& LAHAYE, L. Os professores face ao saber: esboço de uma problemática do saber docente. Teoria \& Educação, 4, 1991, p. 133-215.

TARDIF, M. Saberes docentes e formação profissional. Petrópolis, Brasil: Editora Vozes, 2002.

ZEICHNER, K. M. Repensando as conexões entre a formação na universidade e as experiências de campo na formação de professores em faculdades e universidades. Educação, Santa Maria, v. 35, n. 3, p. 479-504, set./dez. 2010. 


\section{RevistAleph}

ZEICHNER, K.; PAYNE, K.; BRAYKO, K. Democratizing teacher education. Journal of Teacher Education, v. 66, n. 2, p. 122-135, 2015.

Data do envio: $15 / 04 / 2020$

Data do aceite: 20/05/2020. 